\title{
Prevalence of mental illness among Aboriginal and Torres Strait Islander people in Queensland prisons
}

\section{Edward B Heffernan MB BS, MPH, FRANZCP, Director \\ Queensland Forensic Mental Health Services}

\section{Kimina C Andersen} BSW,

Statewide Coordinator Indigenous Forensic Mental Health, Queensland

Forensic Menta Health Services

Abhilash Dev BDS, MPH, Research Officer Harm Reduction Branch

Stuart Kinne BA(Hons), PhD, Head, Justice Health Research, ${ }^{2}$ and Adjunct Senior Lecturer ${ }^{3}$

1 Queensland Health, Brisbane, QLD.

2 Centre for Population Health, Burnet Institute Melbourne, VIC

3 School of Population

Health, University of Queensland, Brisbane, QLD.

Ed_Heffernan@ health.qld.gov.au

MJA 2012; 197: 37-41 doi: 10.5694/mjall.11352 boriginal and Torres Strait Islander people are 14 times more likely to be incarcerated than non-Indigenous Australians and represent $26 \%$ of the custodial population, ${ }^{1}$ despite being less than $3 \%$ of the Australian population. ${ }^{2}$ There are complex links between incarceration, social adversity and poor mental health for Indigenous people. ${ }^{3-5}$ While it is recognised that the prevalence of mental disorder among the general prison population is much higher than in the community, ${ }^{6,7}$ knowledge about the prevalence of mental illness among Indigenous people in custody is limited. ${ }^{8}$ This is particularly disconcerting given that the report of the Royal Commission into Aboriginal Deaths in Custody, ${ }^{9}$ released two decades ago, highlighted the need to better understand the mental health of Indigenous Australians in custody.

A recent report on the general health of Aboriginal inmates ${ }^{5}$ suggested that the prevalence of mental disorder among Indigenous inmates was high. Similarly, the high rates of death by drug overdose and suicide, ${ }^{10,11}$ and of hospital admissions for severe mental illness in this group $^{12}$ in the immediate postrelease period, support this premise. Although previous studies have pointed to a high prevalence of mental illness among Indigenous prisoners, ${ }^{8}$ many have suffered from ill defined sampling frames that jeopardise generalisability, a lack of systematic screening within these sampling frames, exclusive reliance on screening instruments to identify possible mental illness and, most importantly, a lack of cultural sensitivity in the conceptualisation of mental illness and study design and implementation.

\section{Abstract}

Objective: To estimate the prevalence of mental disorder in a representative sample of Aboriginal and Torres Strait Islander people in Queensland prisons.

Design, setting and participants: Cross-sectional assessment of mental health using the Composite International Diagnostic Interview (CIDI) and clinical interviews, conducted by Indigenous mental health clinicians who undertook specific training for this purpose, with support from forensic psychiatrists when indicated. We assessed adults who self-identified as Indigenous and were incarcerated in six of the nine major correctional centres across Queensland (housing $75 \%$ of all Indigenous men and $90 \%$ of all Indigenous women in Queensland prisons) between May and June 2008.

Main outcome measures: Diagnoses of anxiety, depressive and substance misuse disorders using the CIDI; diagnosis of psychotic illness determined through psychiatrist interviews supplemented by a diagnostic panel.

Results: We interviewed $25 \%$ of all Indigenous men (347/1381; mean age, 31.5 years) and 62\% of all Indigenous women (72/116; mean age, 29.2 years) incarcerated at the time of our study. The recruitment fraction was $71 \%$ for men and $81 \%$ for women. Among the 396 individuals who completed both the interview and the CIDI, the 12-month prevalence of mental disorder was $73 \%$ among men and $86 \%$ among women. This comprised anxiety disorders (men, 20\%; women, 51\%); depressive disorders (men, $11 \%$; women, $29 \%$ ); psychotic disorders (men, $8 \%$; women, $23 \%$ ) and substance misuse disorders (men, $66 \%$; women, 69\%).

Conclusions: The prevalence of mental disorder among Indigenous adults in Queensland custody is very high compared with community estimates. There remains an urgent need to develop and resource culturally capable mental health services for Indigenous Australians in custody.

The aim of our study was to estimate the prevalence of mental disorders (depressive, anxiety, psychotic and substance misuse disorders) among a large and representative sample of Indigenous prisoners. It employed systematic sampling and gold-standard assessment methods and, for the first time, introduced culturally sensitive methods of diagnosing psychotic illness in Indigenous prisoners.

\section{Methods}

\section{Design and participants}

Participants were sampled from six of the nine high-security correctional centres across Queensland that included both sentenced and remanded prisoners and contained about $75 \%$ of the Indigenous men and $90 \%$ of the Indigenous women in Queensland prisons at the time. Surveys were conducted over an 8-week period in May and June 2008, and the time spent at each centre varied from 1 to 2 weeks. Before visiting the centres, Indigenous inmates were provided with information about the survey in verbal and written form, to ensure that participants understood the purpose and voluntary nature of participation.

Potential participants were identified from the nominal roll on the first day that the researchers visited that correctional centre. Of those who selfidentified as Indigenous (Aboriginal, Torres Strait Islander or both Aboriginal and Torres Strait Islander), all 
women and every third man on the nominal roll were approached to participate in the study. Participants received $\mathrm{A} \$ 10$ for their time. Excluded from the sample were individuals who did not consent to participate and those judged to be unable to provide informed consent or considered too physically or mentally unwell to participate.

\section{Procedure and measures}

Data were collected by face-to-face interviews in confidential settings within the custodial centres. The questionnaire was administered by trained interviewers, contained both quantitative and qualitative domains, and included questions covering demographic, social, custodial, mental health, health care and cultural characteristics.

Interviewers also administered the Composite International Diagnostic Interview (CIDI), version 2.1, using a laptop computer to assess participants for depression and anxiety disorders during the previous 12 months. A modified version of the substance misuse disorder module was administered, with questions about substance use directed at the 12 months before incarceration to cater for the incarcerated population.

The CIDI is a comprehensive, well validated, fully standardised interview that can be used to assess mental health disorders according to the criteria in the International statistical classification of diseases and related health problems, 10th revision. ${ }^{13}$ Individuals can meet diagnostic criteria for more than one mental disorder; we anticipated that co-occurring disorders were likely. Although the CIDI has not been validated for an Australian Indigenous population, it was chosen because (i) the Indigenous mental health experts consulted in the design of our research judged that it was appropriate to diagnose depression, anxiety and substance misuse disorders in this population, and (ii) it has been widely used with Indigenous populations in other large prisoner studies $^{14}$ and in major national mental health epidemiological surveys. ${ }^{15}$

To prevent culturally congruent experiences being misinterpreted as psychotic experiences, ${ }^{16}$ the full CIDI interview was not used to identify

\begin{tabular}{|c|c|c|c|}
\hline Characteristic & $\begin{array}{l}\text { No. of men } \\
(n=347)\end{array}$ & $\begin{array}{c}\text { No. of women } \\
(n=72)\end{array}$ & Total no. \\
\hline \multicolumn{4}{|l|}{ Indigenous status } \\
\hline Aboriginal & $276(79.5 \%)$ & $58(80.6 \%)$ & $334(79.7 \%)$ \\
\hline Torres Strait Islander & $33(9.5 \%)$ & $4(5.6 \%)$ & $37(8.8 \%)$ \\
\hline Aboriginal and Torres Strait Islander & $38(11.0 \%)$ & $10(13.9 \%)$ & $48(11.5 \%)$ \\
\hline Currently in a relationship & $174(50.1 \%)$ & $29(40.3 \%)$ & $203(48.4 \%)$ \\
\hline Education $\leqslant$ Year 10 & $276(79.5 \%)$ & $60(83.3 \%)$ & $336(80.2 \%)$ \\
\hline Primary income from social welfare & $197(56.8 \%)$ & $62(86.1 \%)$ & $259(61.8 \%)$ \\
\hline \multicolumn{4}{|l|}{ Custodial status } \\
\hline Remanded & $109(31.4 \%)$ & $32(44.4 \%)$ & $141(33.7 \%)$ \\
\hline Sentenced & $231(66.6 \%)$ & $36(50.0 \%)$ & $267(63.7 \%)$ \\
\hline Unknown & $7(2.0 \%)$ & $4(5.6 \%)$ & $11(2.6 \%)$ \\
\hline \multicolumn{4}{|l|}{ Previous incarceration } \\
\hline First time & $61(17.6 \%)$ & $19(26.4 \%)$ & $80(19.1 \%)$ \\
\hline $2-3$ times & $113(32.6 \%)$ & $22(30.6 \%)$ & $135(32.2 \%)$ \\
\hline $4-5$ times & $70(20.2 \%)$ & $11(15.3 \%)$ & $81(19.3 \%)$ \\
\hline$\geqslant 6$ times & $94(27.2 \%)$ & $18(25.0 \%)$ & $112(26.7 \%)$ \\
\hline Not known & $9(2.6 \%)$ & $2(2.8 \%)$ & $11(2.6 \%)$ \\
\hline
\end{tabular}

psychotic disorders; instead, we adopted a three-step process. First, the sample was screened with the CIDI psychosis screener, included in the questionnaire, to identify potential cases. Second, those who screened positive underwent face-toface interviews with a forensic psychiatrist, who used the interview and all available clinical data to determine the presence or absence of a diagnosis. Third, this information, recorded in a standardised format, was reviewed by a diagnostic panel comprised of two psychiatrists and a cultural adviser (an Indigenous mental health clinician) to reach a consensus diagnosis.

The members of the research team were predominantly Indigenous Australians and all were qualified mental health care professionals. They were trained in the use of the research tools, and ethical and emergency care procedures. They were provided with onsite cultural and health care supervision and had access to a psychiatrist and correctional centre health staff if required. The study involved Indigenous people in the design, implementation, data collection and interpretation of results. The research was supported, monitored and informed by a comprehensive consultation process with both Aboriginal and Torres Strait Islander community members.

\section{Ethics approval}

The study design and protocol were approved by the Queensland Health West Moreton Health Service District Human Research Ethics Committee and were consistent with guidelines for ethical conduct in Aboriginal and Torres Strait Islander health research. ${ }^{17}$

\section{Data analysis}

Quantitative data were analysed using Stata, version 12.0 (StataCorp, College Station, Tex, USA); descriptive statistics were reported, and the relative risk of diagnosis by sex was determined.

\section{Results}

On 30 June 2008, there were 5544 adults in Queensland prisons, ${ }^{18}$ of whom 1381 men and 116 women identified as Indigenous. In the six centres surveyed, there were 1036 Indigenous men and 88 Indigenous women.

Of the 487 men approached to participate in the study, 347 (71.3\%) were interviewed, 92 declined to participate, 45 were released, transferred or not available, and three were judged too unwell to be seen due to mental illness. The mean age of male participants was 31.5 years $(S D, 9.4)$ and of the male non-participants was 28.8 years (SD, 8.18); this difference was 
statistically significant $(P=0.03)$. Of the 88 women approached to participate in the study, 72 (81.2\%) were interviewed, 10 declined to participate, five were either released or not available, and one was judged too unwell to be seen due to a physical illness. There was no statistically significant difference in the mean age of female participants (29.2 years; SD, 8.5) and non-participants (30.47 years; SD, 8.35) $(P>0.05)$.

Of the 419 individuals who participated in the study, all completed the questionnaire and were screened for psychosis; 396 (94.5\%) of these individuals also completed the CIDI automated interviews for anxiety, depressive and substance misuse disorders (331 men and 65 women). Of the 23 individuals who did not complete the CIDI, six (three men and three women) were diagnosed with a psychotic disorder.

\section{Demographics and custodial experience}

Most participants (79.7\%) identified as Aboriginal, about half (51.6\%) were not in a relationship and almost two-thirds (61.8\%) were unemployed (Box 1). Most did not complete education beyond Year 10; of these, around a quarter of men $(23.0 \%)$ and a fifth of women (19.4\%) did not complete Year 8 schooling. Almost two-thirds (63.7\%) were sentenced prisoners; the remainder were individuals who were remanded in custody. Nearly half $(46.1 \%)$ had been incarcerated four or more times. Over half the men (52.2\%) and $37.5 \%$ of the women reported having spent time in youth custody, with $23.1 \%$ of men and $9.7 \%$ of women having spent more than a year in youth custody.

\section{Prevalence of mental health disorders}

Of the 396 individuals who completed both the questionnaire and the CIDI, most men $(72.8 \%)$ and women $(86.1 \%)$ suffered from at least one mental health disorder in the preceding 12 months (Box 2). Two-thirds (66\%) suffered from a substance misuse disorder, $25.2 \%$ from an anxiety disorder, $14.3 \%$ from a depressive disorder, and $10.1 \%$ from a psychotic disorder. Mental health disorders were more common among the remanded sample $(84.4 \%)$ than in the sentenced sample $(70.4 \%)$ (relative risk $[R R], 1.12 ; 95 \% \mathrm{CI}, 1.08-1.33 ; P=$ 0.002).

Women were significantly more likely than men to report suffering from an anxiety disorder $(\mathrm{RR}=2.5$; 95\% CI, 1.8-3.5), a depressive disorder $(\mathrm{RR}=2.6$; 95\% CI, 1.6-4.1) or a psychotic disorder $(\mathrm{RR}=3.1 ; 95 \% \mathrm{CI}$, 1.8-5.3). The most common anxiety disorder among both men and women was post-traumatic stress disorder and the most prevalent depressive disorder was major depression (Box 3).

Of the 419 individuals administered the CIDI psychosis screener, 71 (16.9\%) screened positive. Of these, eight men and one woman were unable to be assessed by a psychiatrist as they were either released or transferred before the assessment. Of the remaining 62 individuals, 28 men and 18 women were found to have a psychotic disorder (Box 4).

The majority of both men and women had a substance misuse disorder (Box 5), most commonly alcohol dependence $(48.2 \%)$ or cannabis dependence $(21.0 \%)$. Most individuals who had a substance misuse disorder had the more severe form dependence.

\section{Discussion}

Among the Indigenous inmates sampled, most men and women were diagnosed with at least one mental
2 Twelve-month prevalence of mental health disorder among Indigenous people in Queensland prisons, May-June 2008 $(n=396) *$

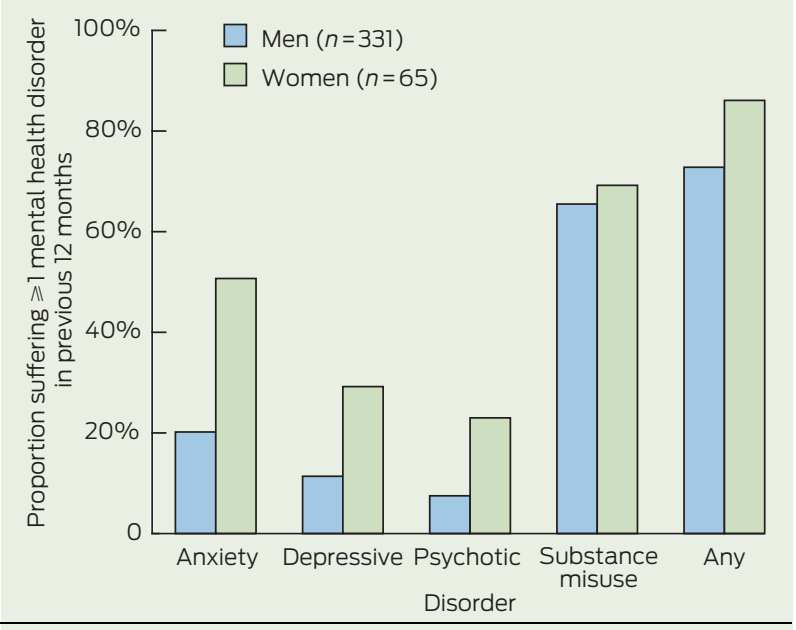

* For comparability purposes, excludes the 23 participants who did not complete the Composite International Diagnostic Interview.

disorder, whereas the 12-month prevalence of mental disorder among adults in the Australian community is estimated at $20 \% .^{15}$ Given the vast overrepresentation of Indigenous people in prison, their frequent transition between prison and the community, and the high prevalence estimates of mental disorder in this group, the consequences of inadequate health care in prison ${ }^{7,19}$ must inevitably affect Indigenous communities. The prevalence of depression and anxiety disorders, especially posttraumatic stress disorder, was high in this sample, and is similar to prevalence estimates of general prison populations, ${ }^{14}$ highlighting the critical

\begin{tabular}{|c|c|c|c|}
\hline Mental disorder & $\begin{array}{l}\text { No. of men } \\
(n=331)\end{array}$ & $\begin{array}{l}\text { No. of women } \\
\quad(n=65)\end{array}$ & $P$ \\
\hline \multicolumn{4}{|l|}{ Anxiety } \\
\hline Panic disorders & $2(0.6 \%)$ & $3(4.6 \%)$ & 0.008 \\
\hline Agoraphobia & $5(1.5 \%)$ & $4(6.2 \%)$ & 0.05 \\
\hline Social phobia & $4(1.2 \%)$ & $8(12.3 \%)$ & $<0.001$ \\
\hline Generalised anxiety disorder & $8(2.4 \%)$ & $3(4.6 \%)$ & $>0.05$ \\
\hline Specific phobias & $15(4.5 \%)$ & $14(21.5 \%)$ & $<0.001$ \\
\hline Obsessive compulsive disorder & $4(1.2 \%)$ & 0 & $>0.05$ \\
\hline Post-traumatic stress disorder & $40(12.1 \%)$ & $21(32.3 \%)$ & $<0.001$ \\
\hline Any anxiety disorder ${ }^{\dagger}$ & $67(20.2 \%)$ & $33(50.8 \%)$ & $<0.001$ \\
\hline \multicolumn{4}{|l|}{ Depression } \\
\hline Major depressive episode & $34(10.3 \%)$ & $15(23.1 \%)$ & 0.004 \\
\hline Dysthymic disorder & $9(2.7 \%)$ & $7(10.8 \%)$ & 0.003 \\
\hline Total depressive disorders $^{\dagger}$ & $38(11.5 \%)$ & $19(29.2 \%)$ & $<0.001$ \\
\hline
\end{tabular}


4 Twelve-month prevalence of psychotic disorder among Indigenous people in Queensland prisons, May-June $2008(n=419)$

\begin{tabular}{lccrr} 
Disorder & $\begin{array}{c}\text { No. of men } \\
(n=347)\end{array}$ & $\begin{array}{c}\text { No. of women } \\
(n=72)\end{array}$ & $P$ & Total \\
\hline Schizophrenia & $15(4.3 \%)$ & $9(12.5 \%)$ & 0.007 & $24(5.7 \%)$ \\
Substance-induced psychotic disorder & $7(2.0 \%)$ & $7(9.7 \%)$ & $<0.001$ & $14(3.3 \%)$ \\
Schizoaffective disorder & $4(1.2 \%)$ & 0 & $>0.05$ & $4(1.0 \%)$ \\
Psychotic disorder (not otherwise specified) & $2(0.6 \%)$ & $2(2.8 \%)$ & $>0.05$ & $4(1.0 \%)$ \\
Any psychotic disorder & $28(8.1 \%)$ & $18(25.0 \%)$ & $<0.001$ & $46(11.0 \%)$
\end{tabular}

need for adequate mental health services in prison settings. ${ }^{7}$ The high prevalence of diagnosed psychotic disorder, particularly among women, is of concern and is consistent with other Australian studies. ${ }^{14,20}$ Psychotic disorder is associated with significant morbidity ${ }^{21}$ and increased risk of reincarceration. ${ }^{22}$ These findings highlight a critical mental health need for these individuals, both in custody and during the transition back to their communities.

This study, like others before it, ${ }^{8}$ identified a high rate of substance use problems among Indigenous prisoners. However, most previous studies have relied exclusively on screening instruments to do this, whereas our study has, for the first time, robustly estimated the diagnostic prevalence of harmful levels of substance misuse and dependence among Indigenous prisoners. The National Indigenous Drug and Alcohol Committee recently highlighted the lack of opportunities that exist for Indigenous people to access appropriate treatment for these problems in custody. ${ }^{23}$ It suggested that, if available, culturally appropriate interventions are likely to be successful, and it provided clear recommendations about how to implement these services. Evaluation of such services, in a way that is both culturally sensitive and scientifically rigorous, is an essential next step.

Sampling is a challenge for any research with custodial populations, due to difficulties accessing all custodial centres and because of daily releases, transfers and receptions. However, given the centres that we sampled contained $75 \%$ of all Indigenous men and $90 \%$ of all Indigenous women in custody at that time, and the high recruitment fractions for both populations, it is likely that the risk of sampling bias was minimised. Similarly, the risk of recall bias is likely to have been reduced by using 12 month prevalence estimates for mental disorders. It is possible that such high estimates of psychotic disorder, particularly among women, might indicate measurement bias. However, given the comprehensive and culturally sensitive method used to make the diagnosis, we believe that these findings are accurate. Further, any measurement bias would be at least partially offset by likely underdetection of psychotic disorders, due to false-negative results on the psychosis screener and the loss from the sample of some individuals who screened positive but could not substances, and other stimulants. undergo diagnostic interviews due to their release.

The small age difference between participating and non-participating men (about 2.5 years) is unlikely to have substantially biased our prevalence estimates, given the size of the male sample and that the mean age of this sample (31.5 years) was similar to that of the total Indigenous male population in Queensland prisons at the time of the survey (30.6 years). A key strength of our research was the extensive consultation conducted with both Aboriginal and Torres Strait Islander communities and the involvement of Indigenous people in all aspects of the research process. Inevitably, cultural bias is a risk in this field of research. We aimed to ensure that any cultural bias or response bias was minimised through the use of a culturally informed research method and trained, culturally competent interviewers.

The information obtained from our research is crucial to the planning and implementation of adequate mental

\begin{tabular}{|c|c|c|c|c|}
\hline ICD-10 diagnosis & $\begin{array}{l}\text { No. of men } \\
(n=331)\end{array}$ & $\begin{array}{l}\text { No. of women } \\
\quad(n=65)\end{array}$ & $P$ & Total \\
\hline Alcohol & $170(51.4 \%)$ & $39(60.0 \%)$ & $>0.05$ & $209(52.8 \%)$ \\
\hline Dependence & 155 (46.8\%) & $36(55.4 \%)$ & $>0.05$ & 191 (48.2\%) \\
\hline Harmful misuse & $15(4.5 \%)$ & $3(4.6 \%)$ & $>0.05$ & $18(4.5 \%)$ \\
\hline Amphetamine & $36(10.9 \%)$ & $4(6.2 \%)$ & $>0.05$ & $40(10.1 \%)$ \\
\hline Dependence & 34 (10.3\%) & $4(6.2 \%)$ & $>0.05$ & 38 (9.6\%) \\
\hline Harmful misuse & $2(0.6 \%)$ & 0 & $>0.05$ & $2(0.5 \%)$ \\
\hline Cannabis & $70(21.1 \%)$ & $17(26.2 \%)$ & $>0.05$ & 87 (22.0\%) \\
\hline Dependence & 66 (19.9\%) & $17(26.2 \%)$ & $>0.05$ & $83(21.0 \%)$ \\
\hline Harmful misuse & $4(1.2 \%)$ & 0 & $>0.05$ & $4(1.0 \%)$ \\
\hline Opioids & $32(9.7 \%)$ & $7(10.8 \%)$ & $>0.05$ & 39 (9.8\%) \\
\hline Dependence & $32(9.7 \%)$ & $7(10.8 \%)$ & $>0.05$ & 39 (9.8\%) \\
\hline Harmful misuse & 0 & 0 & $>0.05$ & 0 \\
\hline Sedatives & $6(1.8 \%)$ & $4(6.2 \%)$ & $>0.05$ & $10(2.5 \%)$ \\
\hline Dependence & 0 & $1(1.5 \%)$ & $>0.05$ & $1(0.3 \%)$ \\
\hline Harmful misuse & $6(1.8 \%)$ & $3(4.6 \%)$ & $>0.05$ & $9(2.3 \%)$ \\
\hline Others ${ }^{\dagger}$ & 28 (8.5\%) & $11(16.9 \%)$ & $>0.05$ & 39 (9.8\%) \\
\hline Dependence & $24(7.3 \%)$ & $11(16.9 \%)$ & $>0.05$ & 35 (8.8\%) \\
\hline Harmful misuse & $4(1.2 \%)$ & 0 & $>0.05$ & $4(1.0 \%)$ \\
\hline Any substance & 217 (65.6\%) & 45 (69.2\%) & $>0.05$ & $262(66.2 \%)$ \\
\hline Dependence & $208(62.8 \%)$ & $43(66.2 \%)$ & $>0.05$ & 251 (63.4\%) \\
\hline Harmful misuse & $23(6.9 \%)$ & $3(4.6 \%)$ & $>0.05$ & $26(6.6 \%)$ \\
\hline
\end{tabular}

ICD-10 = International statistical classification of diseases and related health problems, 10th revision. * For comparability purposes, excludes the 23 participants who did not complete the Composite International Diagnostic Interview. † Includes hallucinogens, volatile solvents and psychoactive 
health services for Indigenous people in contact with and leaving the criminal justice system. For mental health services to be effective, they must be culturally capable, and accessible both in custody and in the community, with a focus on enabling continuity of care between the two. Such services can only be achieved through appropriate resourcing and stewardship. Their development is not only supported from a public health perspective, but also from human rights and ethical perspectives. ${ }^{24,25}$

While the marked over-representation of Indigenous people in Australian prisons remains a significant concern, prisons provide an opportunity for health care for a population who underaccess health care in the community. ${ }^{26}$ Although reducing the Indigenous incarceration rate remains a priority, improving the mental health of Indigenous Australians, including those who come into contact with the criminal justice system, is also important. Access to appropriate treatment may help prevent the "revolving door" of incarceration.

Our study, the first of its kind in Australia, provides an opportunity for service planning and policymaking to be based on reliable estimates of the nature, type and extent of mental disorder among Indigenous people in custody. In embracing the challenge of closing the Indigenous health gap, it is critical that the mental health problems of Indigenous people in custody be addressed.

Acknowledgements: We acknowledge the significant contributions of Aboriginal and Torres Strait Islander communities in Queensland and the Queensland Health Indigenous mental health workforce. We thank Queensland Corrective Services for supporting our research. This research was funded by the Mental Health Alcohol and Other Drugs Directorate, Queensland Health. Stuart Kinner is supported by National Health and Medical Research Council Career Development Fellowship No. 1004765.

Competing interests: No relevant disclosures.
Received 21 Oct 2011, accepted 5 Mar 2012.

1 Australian Bureau of Statistics. Prisoners in Australia, 2010. Canberra: ABS, 2010. (ABS Cat. No. 4157.0.) http://www.abs.gov.au/AUSSTATS/ abs@.nsf/Lookup/4517.0Main+Features12010? OpenDocument (accessed Mar 2012).

2 Australian Bureau of Statistics. Population distribution, Aboriginal and Torres Strait Islander Australians, 2006. Canberra: ABS, 2007. (ABS Cat. No. 4705.0.) http://www.abs.gov.au/ ausstats/abs@.nsf/mf/4705.0 (accessed Mar 2012).

3 Krieg AS. Aboriginal incarceration: health and social impacts. Med J Aust 2006; 184: 534-536.

4 Weatherburn D, Snowball L, Hunter B. The economic and social factors underpinning Indigenous contact with the justice system: results from the 2002 NATSISS. Crime and Justice Bulletin 2006; 104: 1-16. http://www.bocsar.nsw. gov.au/lawlink/bocsar/l_bocsar.nsf/vwFiles/ cjb104.pdf/\$file/cjb104.pdf (accessed Mar 2012).

5 Indig D, McEntyre E, Page J, Ross B. 2009 NSW inmate health survey: Aboriginal health report Sydney: Justice Health, 2010. http://www. justicehealth.nsw.gov.au/publications/Inmate Health_Survey_Aboriginal_Health_Report.pdf (accessed Mar 2012).

6 Butler T, Andrews G, Allnutt S, et al. Mental disorders in Australian prisoners: a comparison with a community sample. Aust NZ J Psychiatry 2006; 40: 272-276.

7 White P. Whiteford H. Prisons: mental health institutions of the 21st century? Med J Aust 2006; 185: 302-303.

8 Heffernan E, Andersen K, Kinner S. The insidious problem inside: mental health problems of Aboriginal and Torres Strait Islander people in custody. Australas Psychiatry 2009; 17 Suppl 1: S41-S46.

9 Johnston EC. Royal Commission into Aboriginal Deaths in Custody. National reports. Canberra: AGPS, 1991. http://www.austlii.edu.au/au/other/ IndigLRes/rciadic/ (accessed Mar 2012).

10 Stewart LM, Henderson CJ, Hobbs MS, et al. Risk of death in prisoners after release from jail. Aust N Z J Public Health 2004: 28: 32-36.

11 Kinner SA, Preen DB, Kariminia A, et al. Counting the cost: estimating the number of deaths among recently released prisoners in Australia. Med J A ust 2011; 195: 64-68.

12 Alan J, Burmis M, Preen D, Pfaff J. Inpatient hospital use in the first year after release from prison: a Western Australian population-based record linkage study. Aust N Z J Public Health 2011; 35: 264-269.

13 Andrews G., Peters L. The Cidi-Auto: a computerised diagnostic interview for psychiatry. Discussion paper. Sydney: CRUfAD, St Vincent's Hospital, 2010. http://www.crufad.org/index. php/cidi/discussion-paper (accessed Oct 2011).

14 Butler T, Allnut S, Cain D, et al. Mental disorder in the New South Wales prisoner population. Aust $N$ Z J Psychiatry 2005; 39: 407-413.
15 Slade T, Johnston A, Teeson M, et al. The menta health of Australians 2. Report on the 2007 National Survey of Mental Health and Wellbeing. Canberra: Department of Health and Ageing, 2009. http://www.health.gov.au/internet/main/ publishing.nsf/content/mental-pubs-mmhaust2 (accessed Mar 2012).

16 Parker R, Milroy H. Schizophrenia and related psychoses in the Aboriginal population of Australia. Aboriginal and Islander Health Worker Journal 2003; 27: 17-19.

17 National Health and Medical Research Council. Values and ethics: guidelines for ethical conduct in Aboriginal and Torres Strait Islander health research. Canberra: Commonwealth of Australia, 2003. http://www.nhmrc.gov.au/guidelines/ publications/e52 (accessed Mar 2012).

18 Australian Bureau of Statistics. Prisoners in Australia, 2008. Canberra: ABS, 2008. (ABS Cat. No. 4157.0.) http://www.abs.gov.au/AUSSTATS/ abs@.nsf/Lookup/4517.0Main+Featuresl2008? OpenDocument (accessed Mar 2012).

19 Grace J, Krom I, Maling C, et al. Review of Indigenous offender health. Australian Indigenous Health Bulletin [internet] 2011; 11: 1-20. http://healthbulletin.org.au/articles/ review-of-indigenous-offender-health/ (accessed Mar 2012)

20 Tye CS, Mullen PE. Mental disorders in female prisoners. Aust N Z J Psychiatry 2006; 40 : 266-271.

21 Jablensky A, McGrath, J, Herrman, H, et al. People living with psychotic illness: an Australian study 1997-98. Canberra: Commonwealth of Australia, 1999. http://www.health.gov.au/internet/main/ publishing.nsf/Content/mental-pubs-p-psych (accessed Mar 2012)

22 Fazel S, Yu R. Psychotic disorders and repeat offending: systematic review and meta-analysis. Schizophr Bull 2011; 37: 800-810.

23 National Indigenous Drug and Alcohol Committee. Bridges and barriers: addressing Indigenous incarceration and health. Canberra: Australian National Council on Drugs, 2009. http://www.nidac.org.au/images/PDFs/nidac bridges_and barriers.pdf (accessed Mar 2012).

24 Office of the United Nations High Commissioner for Human Rights. Standard Minimum Rules for the Treatment of Prisoners. 1977. http://www2. ohchr.org/english/law/treatmentprisoners.htm (accessed Oct 2011).

25 Mental Health Consumer Outcomes Task Force. Mental health: statement of rights and responsibilities. Canberra: Commonwealth of Australia, 1991. http://www.health.gov.au/ internet/main/publishing.nsf/content/mentalpubs-m-rights (accessed Mar 2012).

26 Australian Institute of Health and Welfare. The health of Australia's prisoners 2009. Canberra: AlHW, 2010. (AlHW Cat. No. PHE 123.) http:// www.aihw.gov.au/publication-detail/?id= 6442468371 (accessed Mar 2012).
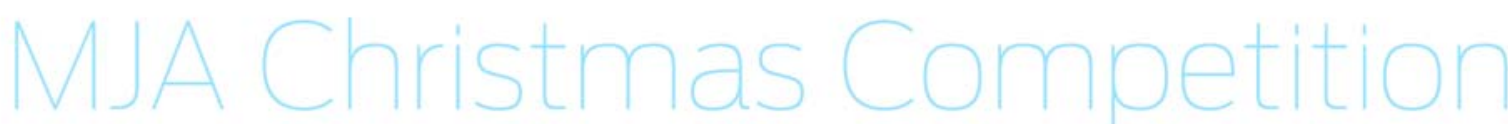

Christmas will soon be here, but there's still time to have your quirky stories, wacky research, amazing images and other eclectica considered for publication in the MJA's festive December issue. Outstanding submissions will be entered as finalists in the MJA Christmas Competition. Consult our instructions for authors and submit by Monday 8 October 2012. 